\title{
THE PRINCIPLE OF LEGAL CERTAINTY AS A GUARANTEE OF EFFECTIVE IMPLEMENTATION OF THE CONSTITUTIONAL RIGHTS AND FREEDOMS OF CITIZENS
}

\author{
Svetlana N. Shabunevich \\ Academy of Public Administration under the President of the Republic of Belarus, Minsk, Belarus
}

\begin{abstract}
Introduction: based on the analysis of scientific approaches and the Belarusian constitutional legislation, the paper examines the problem of the legal regulation of human rights mechanisms of the constitutional rights and freedoms of citizens, identifies such reasons for the unconstitutionality of the regulation of these issues as uncertainty in the legal regulation of the guarantees of the constitutional rights and freedoms of citizens established by the legislation, inaccuracies and difficulties in the presentation of legal norms, the presence of conflicts, etc., which negatively affects the effectiveness of the implementation of legal interests of citizens. Some possible ways of improving the legal regulation of human rights mechanisms of citizens' rights and freedoms are proposed. The category of "legal certainty" is multi-faceted and therefore can manifest itself in all areas of the legal sphere. The universality of the principle of legal certainty is because it ensures the stability of the legal regulation of public relations both in the field of law-making and in the field of law enforcement practice. Ensuring the effectiveness of the legislative regulation of public relations, the principle of legal certainty serves as a criterion for the quality of norm control of the subjects of constitutional justice, is a measure of the assessment of constitutional procedural norms. In the sphere of legislative activity, the principle of legal certainty is the degree of its effectiveness. The qualitative implementation of the principle of legal certainty in the field of the legislative regulation of guarantees of citizens' rights and freedoms directly affects the quality of the law enforcement process. Purpose: to identify the problems of the legal regulation of human rights mechanisms of the constitutional rights and freedoms of citizens. Methods: the methodological framework for the study is a combination of general scientific and special research methods: dialectical, systematic, formal-legal, comparative law, sociological, analytical methods, etc. Results: the paper is devoted to identifying the causes of existing problems of the legal regulation of human rights mechanisms of the constitutional rights and freedoms of citizens and identifying possible ways to solve them. To effectively ensure the constitutional rights and freedoms of citizens, the stability of the legal regulation is important, which can be ensured by an accurate statement of the content of a legal norm that regulates the boundaries of proper and prohibited behavior of all subjects of legal relations designed to ensure the legitimate interests of citizens. The author believes that it is possible to improve the legal regulation of the human rights mechanisms of citizens' rights and freedoms by adopting special laws on the interpretation of articles of the Constitution that establish these guarantees. Conclusions: as a result of the conducted research, it is found that the national Belarusian legislation has formed an effective system for protecting the constitutional rights and freedoms of citizens, and the corresponding procedural mechanisms are fixed. At the same time, the presence of uncertainty in the legal regulation, the guarantees of the constitutional rights and freedoms of the individual established by law, and the inaccuracy of the legal norms directly regulating the sphere of the studied relations often indicate that the existing system of human rights mechanisms for the legitimate interests of citizens fully ensures their implementation and needs to be improved.

Key words: human rights mechanisms, the principle of legal certainty, restrictions on rights and freedoms, compensation for damages, official.

Citation. Shabunevich S.N. The Principle of Legal Certainty As a Guarantee of Effective Implementation of the Constitutional Rights and Freedoms of Citizens. Legal Concept = Pravovaya paradigma, 2021, vol. 20, no. 3 , pp. 88-93. (in Russian). DOI: https://doi.org/10.15688/lc.jvolsu.2021.3.14
\end{abstract}




\title{
ПРИНЦИП ПРАВОВОЙ ОПРЕДЕЛЕННОСТИ КАК ГАРАНТИЯ ЭФФЕКТИВНОЙ РЕАЛИЗАЦИИ КОНСТИТУЦИОННЫХ ПРАВ И СВОБОД ГРАЖДАН
}

\author{
Светлана Николаевна Шабуневич \\ Академия управления при Президенте Республики Беларусь, г. Минск, Беларусь
}

\begin{abstract}
Введение: в статье на основе анализа научных подходов и белорусского конституционного законодательства исследована проблема правовой регламентации правозащитных механизмов конституционных прав и свобод граждан, выявлены такие причины неконституционности регулирования данных вопросов, как неопределенности в правовой регламентации установленных законодательством гарантий конституционных прав и свобод граждан, неточности и сложности в изложении правовых норм, наличие коллизий и проч., что негативно отражается на эффективности реализации законных интересов граждан. Предложены возможные пути совершенствования правовой регламентации правозащитных механизмов прав и свобод граждан. Категория «правовая определенность» многогранна и поэтому может проявляться во всех областях правовой сферы. Универсальность принципа правовой определенности обусловлена тем, что он обеспечивает стабильность правового регулирования общественных отношений как в сфере правотворчества, так и в сфере правоприменительной практики. Обеспечивая эффективность законодательного регулирования общественных отношений, принцип правовой определенности служит критерием качества нормоконтроля субъектов конституционного правосудия, является мерилом оценки конституционных процессуальных норм. В сфере законотворческой деятельности принцип правовой определенности являет собой степень ее эффективности. Качественное воплощение принципа правовой определенности в сфере законодательной регламентации гарантий прав и свобод граждан напрямую влияет на качество правоприменительного процесса. Цель: выявить проблемы правового регулирования правозащитных механизмов конституционных прав и свобод граждан. Методы: методологическую основу данного исследования составила совокупность общенаучных и специальных методов исследования: диалектического, системного, формально-юридического, сравнительноправового, социологического, аналитического методов и др. Результаты: данная статья посвящена выявлению причин существующих проблем правового регулирования правозащитных механизмов конституционных прав и свобод граждан и определению возможных путей их решения. В целях эффективного обеспечения конституционных прав и свобод граждан важна стабильность правового регулирования, что может быть обеспечено точным изложением содержания правовой нормы, ясно регламентирующей границы должного и запрещенного поведения всех субъектов правовых отношений, призванных обеспечивать законные интересы граждан. Совершенствование правовой регламентации правозащитных механизмов прав и свобод граждан становится возможным благодаря принятию специальных законов о толковании статей Конституции, устанавливающих указанные гарантии. Выводы: в итоге проведенного исследования установлено, что национальным белорусским законодательством сформирована действенная система защиты конституционных прав и свобод граждан, закреплены соответствующие процессуальные механизмы. При этом зачастую наличие неопределенности в правовой регламентации, установленных законодательством гарантий конституционных прав и свобод личности, неточности правовых норм, непосредственно регулирующих сферу исследуемых отношений, свидетельствуют о том, что сложившаяся система правозащитных механизмов законных интересов граждан в полной мере обеспечивает их реализацию и нуждается в своем совершенствовании.
\end{abstract}

Ключевые слова: правозащитные механизмы, принцип правовой определенности, ограничения прав и свобод, возмещение ущерба, должностное лицо.

Цитирование. Шабуневич С. Н. Принцип правовой определенности как гарантия эффективной реализации конституционных прав и свобод граждан // Legal Concept = Правовая парадигма. -2021 . - T. 20, № 3 . C. 88-93. - DOI: https://doi.org/10.15688/lc.jvolsu.2021.3.14 


\section{Введение}

На современном этапе развития конституционного белорусского законодательства система правозащитных механизмов прав и свобод граждан максимально направлена на соответствие таким важнейшим международно-правовым актам, как Европейская конвенция «О защите прав человека и основных свобод» от 04.11.1950, Международный пакт об экономических, социальных и культурных правах 1966 г., Международный пакт о гражданских и политических правах 1966 года. Основныепринципы и руководящие положения, касающиеся прав на юридическую защиту и возмещение ущерба для жертв грубых нарушений международных норм в области прав человека и серьезных нарушений международного гуманитарного права 2005 г. и др. В развитие положений указанных актов Конституция Республики Беларусь в ч. 2 ст. 21 закрепила гарантии прав и свобод граждан Беларуси, предусмотренные международными обязательствами государства [4]. Таким образом, белорусское государство превентивно обязалось обеспечить всю систему прав и свобод личности, которые соответствуют принципам и нормам международного права. Однако присутствующие неопределенности в правовой регламентации установленных законодательством гарантий конституционных прав и свобод личности, неточности правовых норм, непосредственно регулирующих сферу исследуемых отношений, свидетельствуют о том, что сложившаяся система правозащитных механизмов законных интересов граждан не в полной мере обеспечивает их реализацию и нуждается в своем совершенствовании.

\section{Проблемы правовой регламентации правозащитных механизмов в сфере обеспечения прав и свобод граждан}

Анализ конституционной судебной практики по вопросам применения соответствующего законодательства при рассмотрении судами дел о защите конституционных прав и свобод граждан доказывает, что зачастую неконституционность правового регулирования данных вопросов обусловлена неточностью и неясностью изложения сущности нормы права. Следствием подобного рода правовых де- фектов является невыполнение гарантий государственной (в том числе судебной) защиты прав и свобод граждан, а также нарушение принципов равенства и верховенства закона. Г.А. Василевич отмечает: «Серьезные проблемы для граждан возникают в связи с пробелами в законодательстве, несвоевременным приведением нормативных актов и практикой их применения в соответствие с Конституцией и актами, обладающими по отношению к ним более высокой юридической силой» [1, с. 57].

Стоит также обратить внимание на то, что конституционным законодательством предусматриваются случаи ограничения законных интересов граждан. Именно в такой ситуации неопределенность правовых регламентаций прав и свобод граждан может привести к их незаконному ограничению. Подобные ограничения присутствуют и в ряде международных актов, однако здесь они четко регламентированы. Так, в соответствии с ч. 2 ст. 29 Всеобщей декларации прав человека основанием ограничений законных интересов граждан могут служить: необходимость обеспечения должного признания и уважения прав и свобод других граждан, удовлетворение справедливых требований морали, общественного порядка и общего благосостояния в демократическом обществе [2]. В развитие указанного положения ст. 23 Конституции Республики Беларусь установлены следующие основания ограничения прав и свобод личности: случаи, предусмотренные законом, интересы национальной безопасности, общественного порядка, защиты нравственности, здоровья населения, прав и свобод других лиц [4]. Полагаем, что национальное законодательство обязано идти по пути конкретизации установленных международными актами гарантий прав и свобод граждан, максимально учитывая принцип правовой определенности при их законодательном закреплении.

\section{Влияние неопределенности правовых норм на судебную и правоприменительную практику в сфере реализации законных интересов граждан}

Неопределенность правовых норм в исследуемой сфере оказывает негативное влияние и на правоприменительную судебную 
практику, поскольку влечет возможность правового маневрирования правоприменителя. В связи с отмеченным важную роль в обеспечении законных интересов граждан играет принцип правовой определенности, который одновременно выступает критерием оценки качества норм права и нормативных правовых актов. Напрямую это относится и к четкому и недвусмысленному законодательному закреплению указаний на конкретные субъекты властных структур, действиями которых могут быть нарушены права и своды граждан. Полагаем, что учет такого юридического условия, как принцип правовой определенности, напрямую повлияет на реализацию и защиту конституционных прав личности.

За последнее десятилетие процесс модернизации белорусского законодательства, закрепляющего правовые механизмы защиты прав и свобод граждан, отражает факт последовательной имплементации норм и принципов международного права в национальную правовую систему. Свидетельством тому служит закрепление в белорусской Конституции положений об обязательствах государства в сфере основных прав и свобод личности, а также гарантий их реализации. По мнению конституционалистов, такие права и свободы обладают абсолютным и универсальным характером. При этом в правовом регулировании правозащитных механизмов законных интересов граждан имеются определенные недостатки.

Анализ законодательства Беларуси в исследуемой сфере свидетельствует о том, что нередко в отраслевом законодательстве вопросы защиты законных интересов граждан от неправомерных действий властных субъектов регламентированы по-разному. В соответствии с национальным гражданским законодательством в случае причинения гражданину незаконными действиями государственных органов или должностных лиц этих органов, органов местного управления и самоуправления либо должностных лиц этих органов убытков (вреда), источником их возмещения могут быть государство, казна государства или казна административно-территориальной единицы [3]. При этом отсутствует четкая и ясная регламентация порядка возмещения причиненных убытков. В подобных случаях име- ется общая отсылка к действующему законодательству (п. 2.8 ст. 9 Закона Республики Беларусь «О противодействии монополистической деятельности и развитии конкуренции» [5]) и др. Известные проблемы при реализации законных интересов граждан возникают в связи с наличествующими в законодательстве пробелами, несоответствием нормативных правовых актов и несвоевременным приведением практики применения нормативных правовых актов Конституции, а также актам, которые имеют более высокую юридическую силу. Определенные трудности в обеспечении защитных механизмов прав и свобод граждан обусловлены тем, что в отдельных случаях нормы Конституции противоречат действующей реальности. До настоящего времени не выработаны общепризнанные подходы толкования и непосредственного применения норм Конституции. Полагаем, что подобные правовые конструкции лишь препятствуют эффективной реализации правозащитных механизмов законных интересов граждан. Кроме того, указанные проблемы оказывают негативное влияние на судебную правоприменительную практику.

Конституционный суд Республики Беларусь неоднократно высказывался о необходимости решения проблем, касающихся неточности и противоречивости в регулировании исследуемых отношений. Такой подход в правовом регулировании ослабляет гарантии конституционных прав и свобод и потому недопустим. В данном случае для четкого и недвусмысленного толкования правовой нормы необходимо единообразие ее понимания.

\section{Выводы}

Таким образом, существенным препятствием в эффективной реализации прав и свобод граждан, гарантированных нормами Конституции Республики Беларусь и установленных важнейшими международно-правовыми актами, являются сложность и неопределенность правовых предписаний, наличие коллизионных норм и проч. Важность реализации принципа правовой определенности при регламентации правозащитных механизмов законных интересов граждан заключается в том, что он обеспечивает системность и комплек- 


\section{ТЕОРИЯ И ПРАКТИКА ГОСУДАРСТВЕННО-ПРАВОВОГО РАЗВИТИЯ}

сность правового регулирования исследуемых общественных отношений. Благодаря реализации принципа правовой определенности достигается точность и непротиворечивость правовых норм, их логическая согласованность, ведение четких правил законодательной техники. Только такой подход в правовой регламентации гарантий прав и свобод граждан обеспечит единообразие правоприменительной практики. Совершенствование правовой регламентации правозащитных механизмов прав и свобод граждан становится возможным благодаря принятию специальных законов о толковании статей Конституции, устанавливающих гарантии защиты прав и свобод граждан.

\section{СПИСОК ЛИТЕРАТУРЫ}

1. Василевич, Г. А. Конституционно-правовая ответственность в Республике Беларусь / Г. А. Василевич // Выбраныя навуковыя працы Беларускага дзяржаўнага ўніверсітэта, 1921-2001. У 7 т. Т. 3. Юрыспрудэнцыя. Эканоміка. Міжнародныя адносіны / рэдкал.: В. М. Гадуноў (адк. рэд.) [і інш.]. Мінск, 2001.- С. 54-66.

2. Всеобщая декларация прав человека, принятая резолюцией 217 А (III) Генеральной Ассамблеи ООН от 10 дек. 1948 г. // Права человека : междунар.-правовые документы / сост. В. В. Щербов. Минск, 1999.-- С. 761-772.

3. Гражданский кодекс Республики Беларусь от 7 дек. 1998 г., № 218-3 : принят Палатой представителей 28 окт. 1998 г. : одобр. Советом Респ. 19 нояб. 1998 г. : в ред. Закона Респ. Беларусь от 09.01.2017 // ЭТАЛОН. Законодательство Республики Беларусь, Нац. центр правовой информ. Респ. Беларусь. - Минск, 2021.

4. Конституция Республики Беларусь : 15 марта 1994 г. : с изм. и доп., принятыми на респ. референдумах 24 нояб. 1996 г. и 17 окт. 2004 г. // ЭТАЛОН. Законодательство Республики Беларусь, Нац. центр правовой информ. Респ. Беларусь. - Минск, 2021.

5. О противодействии монополистической деятельности и развитии конкуренции : Закон Респ. Беларусь, 12 дек. 2013 г., № 94-3 // ЭТАЛОН. Законодательство Республики Беларусь, Нац. центр правовой информ. Респ. Беларусь. - Минск, 2021.

\section{REFERENCES}

1. Vasilevich G.A. Konstitucionno-pravovaya otvetstvennost' v Respublike Belarus' [Constitutional and Legal Responsibility in the Republic of Belarus]. Gadunoy V.M. et al., eds. Vybranyya navukovyya pracy Belaruskaga dzyarzhaunaga universiteta, 1921-2001. U 7 t. T. 3. Jurysprudentsyya. Ekanomika. Mizhnarodnyya adnosiny [Selected Scientific Works of Belarusian State University, 1921-2001. In 7 vols. Vol. 3. Jurisprudence. Economy. Foreign Affairs]. Minsk, 2001, pp. 54-66.

2. Shcherbov V.V. Vseobshchaya deklaraciya prav cheloveka, prinyataya rezolyuciej 217 A (III) General'noj Assamblei OON ot 10 dek. 1948 g. [The Universal Declaration of Human Rights, Adopted by the UN General Assembly Resolution 217 A(III) of 10 Dec. 1948]. Prava cheloveka: mezhdunar-pravovye dokumenty [Human Rights: International Legal Documents]. Minsk, 1999, pp. 761-772.

3. Grazhdanskij kodeks Respubliki Belarus' ot 7 dek. 1998 g., 218-Z: prinyat Palatoj predstavitelej 28 okt. 1998 g.: odobr. Sovetom Resp. 19 noyab. 1998 g.: v red. Zakona Resp. Belarus' ot 09.01.2017 g. [Civil Code of the Republic of Belarus: 7 Dec. 1998, No. 218-Z: Adopted by the House of Representatives on October 28, 1998: Approved by the Council of Rep. November 19, 1998: ed. The Law of Rep. Belarus from 09.01.2017]. ETALON. Zakonodatel'stvo Respubliki Belarus', Nac. centr pravovoj inform. Resp. Belarus'. [ETALON. Legislation of the Republic of Belarus, National Center for Legal Information. Republic ofBelarus]. Minsk, 2021.

4. Konstituciya Respubliki Belarus': 15 marta 1994 g.: s izm. i dop., prinyatymi na resp. referendumah 24 noyab. 1996 g. 117 okt. 2004 g. [The Constitution of the Republic of Belarus: March 15, 1994: With Amendments and Additions Adopted at the Rep. Referendums of November 24, 1996 and October 17, 2004]. ETALON. Zakonodatel 'stvo Respubliki Belarus', Nac. centr pravovoj inform. Resp. Belarus'. [ETALON. Legislation of the Republic of Belarus, National Center for Legal Information. Republic ofBelarus]. Minsk, 2021.

5. O protivodejstvii monopolisticheskoj deyatel'nosti i razvitii konkurencii: Zakon Resp. Belarus', 12 dek. 2013 g., 94-Z [On Countering Monopolistic Activity and Developing Competition: Law of the Republic of Belarus. Belarus, 12 Dec. 2013, No. 94-Z]. ETALON. Zakonodatel'stvo Respubliki Belarus', Nac. centr pravovoj inform. Resp. Belarus'. [ETALON. Legislation of the Republic of Belarus, National Center for Legal Information. Republic of Belarus]. Minsk, 2021. 


\section{Information About the Author}

Svetlana N. Shabunevich, Candidate of Sciences (Jurisprudence), Associate Professor, Department of Social and Humanitarian Disciplines, Academy of Public Administration under the President of the Republic of Belarus, Moskovskaya St, 17, 220007 Minsk, Belarus, snshabunevich@yandex.ru, post@pac.by, https://orcid.org/0000-0001-8215-9442

\section{Информация об авторе}

Светлана Николаевна Шабуневич, кандидат юридических наук, доцент кафедры социально-гуманитарных дисциплин, доцент, Академия управления при Президенте Республики Беларусь, ул. Московская, 17, 220007 г. Минск, Беларусь, snshabunevich@yandex.ru, post@pac.by, https://orcid.org/0000-0001-8215-9442 